\title{
Primary intraosseous squamous cell carcinoma derived from a maxillary cyst: A case report and literature review
}

\author{
TAKUMA MORITA $^{1}$, MASASHI YAMASHIRO ${ }^{2}$, KOU KAYAMORI $^{3}$, MIHO MIZUTANI $^{2}$, KOICHI NAKAKUKI $^{1}$, \\ YASUYUKI MICHI $^{1}$, NARIKAZU UZAWA ${ }^{1}$, TOSHIYUKI IZUMO ${ }^{4}$ and KIYOSHI HARADA ${ }^{1}$ \\ ${ }^{1}$ Division of Maxillofacial and Neck Reconstruction, Department of Maxillofacial Reconstruction and Function, \\ Maxillofacial Surgery, Graduate School, Tokyo Medical and Dental University, Tokyo 113-8549; ${ }^{2}$ Department \\ of Dentistry and Oral Surgery, NTT Medical Center, Tokyo 141-8625; ${ }^{3}$ Section of Oral Pathology; \\ ${ }^{4}$ Department of Diagnostic Oral Pathology, Division of Oral Health Science, Oral Restitution, \\ Graduate School, Tokyo Medical and Dental University, Tokyo 113-8549, Japan
}

Received July 6, 2015; Accepted January 8, 2016

DOI: $10.3892 / \operatorname{mco} .2016 .741$

\begin{abstract}
Primary intraosseous squamous cell carcinoma (PIOSCC) is a rare malignant central jaw tumor derived from odontogenic epithelial remnants. PIOSCC predominantly affects the mandible, although both jawbones may be involved. This case report describes a PIOSCC type 2 of the maxilla in a 37-year-old man, treated by partial maxillectomy. Histopathologically, the tumor was diagnosed as PIOSCC derived from an odontogenic cyst. Postoperatively, the patient has been followed up for 53 months, with no recurrence of the disease. We herein describe the clinical details, treatment results and histopathological characteristics of a rare case of PIOSCC derived from a maxillary odontogenic cyst with reference to the relevant literature.
\end{abstract}

\section{Introduction}

Primary intraosseous squamous cell carcinoma (PIOSCC) is a central jaw carcinoma derived from odontogenic epithelial remnants. PIOSCC is defined as a SCC arising within the jaw, and it has no initial connection with the oral mucosa. This tumor was first described by Loos (1) in 1913 as a central epidermoid carcinoma of the jaw. Willis (2) renamed the tumor as intraalveolar epidermoid carcinoma in 1948. In 1972 , Pindborg et al (3) suggested the term primary intraosseous carcinoma (PIOC) and classified the lesion as an odontogenic carcinoma. Subsequently, the classification of odontogenic carcinomas was modified in several studies (4-6). In 2005, Eversole et al (7) introduced the term 'primary intraosseous SCC' (PIOSCC) and further categorized this entity into

Correspondence to: Dr Masashi Yamashiro, Department of Dentistry and Oral Surgery, NTT Medical Center, 5-9-22 Higashigotanda, Shinagawa-Ku, Tokyo 141-8625, Japan E-mail: myamashiro2@gmail.com

Key words: primary intraosseous squamous cell carcinoma, maxilla, odontogenic cyst
3 types: Type 1 for solid tumors, type 2 for carcinomas arising from odontogenic cysts and type 3 for carcinomas associated with odontogenic tumors.

In PIOSCC type 2, an SCC results from malignant transformation of an odontogenic cyst. To establish the presence of such malignant transformation, certain diagnostic criteria must be fulfilled (8). The estimated incidence of PIOSCC type 2 has been shown to range from 0.1 to $1.8 \%$ of all oral cancers (9-12). Bodner et al analyzed 116 reported cases of PIOSCC arising in an odontogenic cyst and found that the tumors predominantly affected the mandible, whereas the maxilla was affected in $21 \%$ of the cases (13).

We herein report a case of PIOSCC derived from a maxillary odontogenic cyst. We have also reviewed the literature for cases of PIOSCC arising from maxillary cysts, including keratocystic odontogenic tumors, with respect to the diagnosis, prognosis and treatment of these tumors. Written informed consent was obtained from the patient for the publication of his case details.

\section{Case report}

In August, 2010, a 37-year-old Japanese man visited the Department of Oral Surgery in another hospital, with a 4-month history of a painful swelling in the left maxillary gingiva. Following clinical examination, the patient was diagnosed with apical periodontitis and antibiotics were prescribed; however, no improvement was noted. In October, 2010, the patient presented with a fistula in the left maxillary gingiva. A computed tomography (CT) scan revealed an area of bone resorption in the lateral nasal wall. The histopathological examination of the biopsy specimen indicated suspected SCC. The patient was then referred to the Dental Hospital of Tokyo Medical and Dental University (Tokyo, Japan) for extensive examination and treatment.

Extraoral examination revealed a swelling without paresthesia in the left buccal region. Intraoral examination revealed a painful ulcer in the maxillary buccal gingiva of the left canine, caused by the previous biopsy (Fig. 1). A panoramic radiograph revealed no obvious cyst-like radiolu- 
cent lesion (Fig. 2); however, a contrast-enhanced CT revealed a soft tissue mass $\left(30 \times 16 \times 22 \mathrm{~mm}^{3}\right)$ with irregular borders and heterogeneous density in the left anterior maxilla, which had invaded and damaged the left lateral nasal wall and the left bottom edge of the left maxillary sinus (Fig. 3A and B). Contrast-enhanced magnetic resonance imaging (MRI) revealed a high-density lesion on T2-weighted images, indicating expansion of the tumor to the base of the left nasal ala (Fig. 3C and D). The previous biopsy specimen from the referring hospital was reevaluated and diagnosed as suspected odontogenic carcinoma.

Based on this diagnosis of odontogenic carcinoma, surgical treatment was scheduled. In November, 2010, the patient underwent partial maxillectomy through a Weber-Ferguson incision. Due to suspected tumor infiltration of the soft tissues at the base of the left nasal ala, part of the skin was simultaneously resected. Following resection, the raw surface of the buccal soft tissues was covered using a full-thickness skin graft from the groin. An intraoral incision was made from the right maxillary central incisor area to the left maxillary first molar area. The upward incision line was set under $5 \mathrm{~mm}$ from the infraorbital margin (Fig. 4). The postoperative course was uneventful, and a maxillary prosthesis was placed. A follow-up fluorodeoxyglucose-positron emission tomography (FDG-PET) scan revealed no recurrence, metastasis, or carcinoma in other regions. The patient has been followed up for 53 months, with no recurrence of the disease.

The histological examination revealed a centrally located tumor within the maxillary bone, without any connection to the oral or maxillary sinus mucosa, consisting of solid and cystic components (Fig. 5A). The solid components exhibited islands of neoplastic squamous epithelium with keratinization and central necrosis of the tumor nests (Fig. 5B). By contrast, in the cystic components, the lining epithelium consisted of parakeratinized squamous epithelium. However, palisaded basal cells, typically seen in keratocystic odontogenic tumors, were not identified in the lining epithelium. Parts of the lining epithelium exhibited moderate to severe dysplastic changes (Fig. 5C), with focal areas of transition to invasive keratinized SCC nests (Fig. 5D). Based on the clinical data and histopathological findings, this lesion was diagnosed as a PIOSCC derived from an odontogenic cyst.

\section{Discussion}

PIOSCC is a rare central jaw carcinoma derived from odontogenic epithelial remnants. According to the 2005 World Health Organisation Classification of Tumours, the subcategories of PIOSCC include a solid tumor that invades marrow spaces and induces osseous resorption (type 1), an SCC arising from the lining of an odontogenic cyst (type 2) and an SCC in association with other benign epithelial odontogenic tumors (type 3) (7). The present case was classified as type 2, as it fulfilled the criteria detailed below.

In 1975, Gardner (8) proposed the following criteria for the diagnosis of SCC arising in an odontogenic cyst: i) It should be confirmed histologically that the epithelial lining of the cyst has undergone malignant transformation to SCC; ii) clinical examinations should reveal no SCC of the gingiva or oral mucosa and the reported neoplasms should be centrally located within the bone tissue of the jaws; and iii) no primary neoplasm at distant sites should be detected.

A fourth criterion was later added by Waldron and Mustoe: The possibility that the lesion in question represents a metastasis from a distant primary tumor must be ruled out by physical and radiological examinations and the subsequent clinical course (6).

With regard to the present case, the microscopic examination revealed the presence of a cyst consisting of both normal stratified squamous epithelium and SCC. Histopathologically, the resected specimen exhibited an area of transition from normal cystic epithelium to invasive SCC, along with normal oral mucosa. This is a noteworthy finding, as in previous studies the carcinoma destroyed the odontogenic cyst, rendering it difficult to determine the actual site of malignant transformation (14) Moreover, follow-up FDG-PET scans showed no carcinoma in any other areas. Therefore, we considered the tumor in our patient to fulfil all of Gardner's criteria; accordingly, PIOSCC arising from an odontogenic cyst (type 2) was diagnosed.

In retrospect, it was difficult to diagnose this lesion as a malignant tumor based on the intraoral examination and the panoramic radiograph prior to treatment. CT and MRI examinations showed malignant findings but did not reveal the presence of the cyst. These factors suggest the significance of a histopathological examination and confirmation of the diagnosis prior to initial treatment.

Bodner et al (13) analyzed 116 reported cases of PIOSCC arising in an odontogenic cyst and found that the majority of the cases exhibited mandibular involvement, whereas the maxilla was affected in $21 \%$ of the cases. For the present report, we searched for cases of PIOSCC derived from a maxillary odontogenic cyst. A review of 29 cases, including the present case, is presented in Table I $(9-12,15-37)$. In the 29 cases, the patient age ranged from 14 to 79 years, with a mean age of 47.0 years. The male:female ratio was $2.5: 1$. The most common clinical symptom was swelling $(72.7 \%, 16 / 22)$ with or without pain. The most common initial treatment approach was enucleation or local resection $(48.0 \%, 12 / 25)$ under the diagnosis of odontogenic cyst, and none of these 12 patients had undergone a preliminary biopsy. In the majority of the patients, additional operations, such as maxillectomy, were performed. However, 8 cases $(40.0 \%, 8 / 20)$ were histologically confirmed as malignant tumors by biopsy prior to initial treatment. Postoperative treatment was administered to 9 patients (radiation therapy, $\mathrm{n}=8$; and chemoradiation, $\mathrm{n}=1$ ).

Neck metastases from PIOSCC derived from maxillary odontogenic cysts are rare, with only 4 cases $(19.0 \%, 4 / 21)$ reported to date. Nomura et al (38) reported that the probability of lymph node metastasis was 4.4\% (5/113) in PIOSCC type 2. Thus, neck dissection should be performed only when required.

Overall, 10 patients were followed up for $>2$ years and 3 patients succumbed ( 2 deaths were caused by cancer and 1 was due to another disease). In the 2 cancer deaths, a preliminary biopsy had not been performed. The 2-year survival rate was $83.3 \%$ (10/12). Chantravekin et al (39) reported that the 2-year survival rate was $60.0 \%$, while Bodner et al (13) reported that the 2- and 5-year survival rates were 62 and 38\%, respectively. There were significant differences in survival rate between the present study and previous reports. An underlying reason 


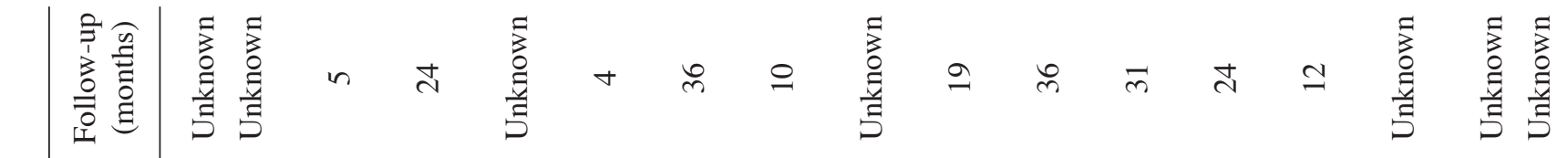

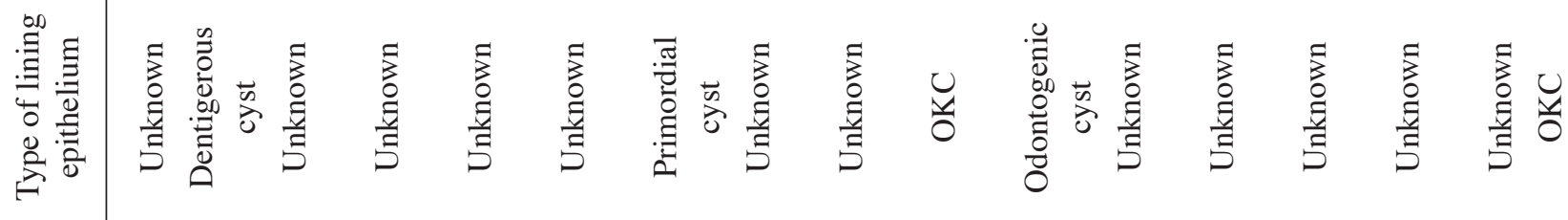

$$
\begin{aligned}
& \text { 交 }
\end{aligned}
$$

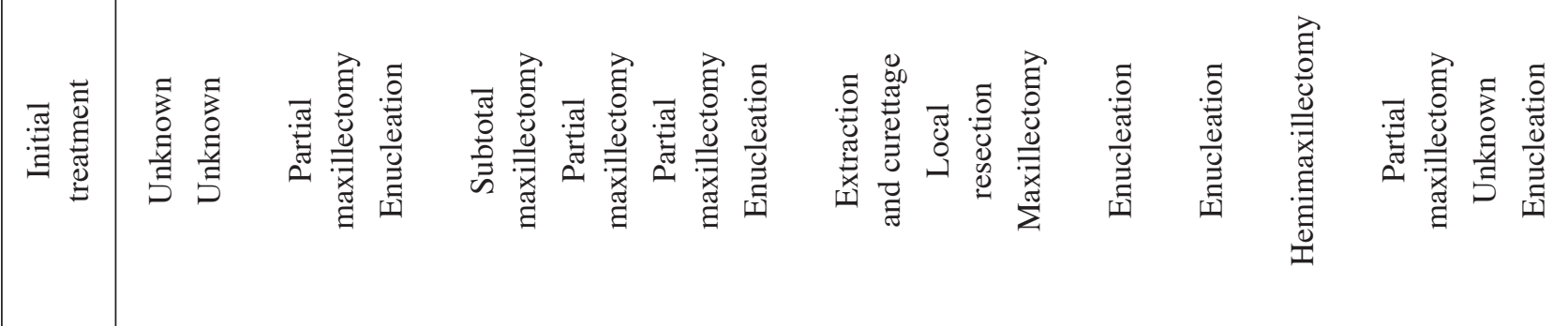

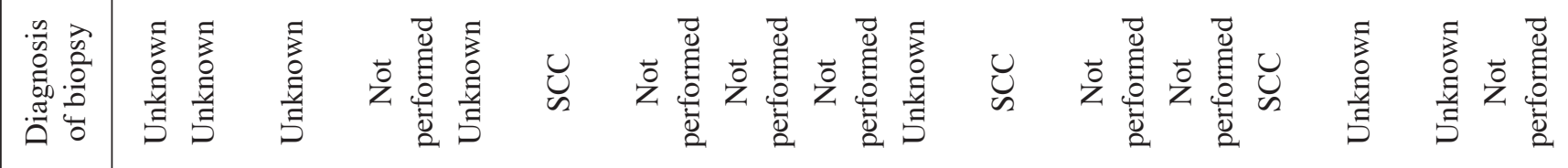

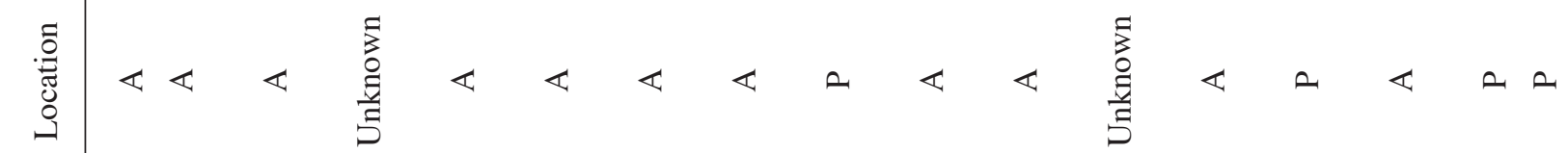

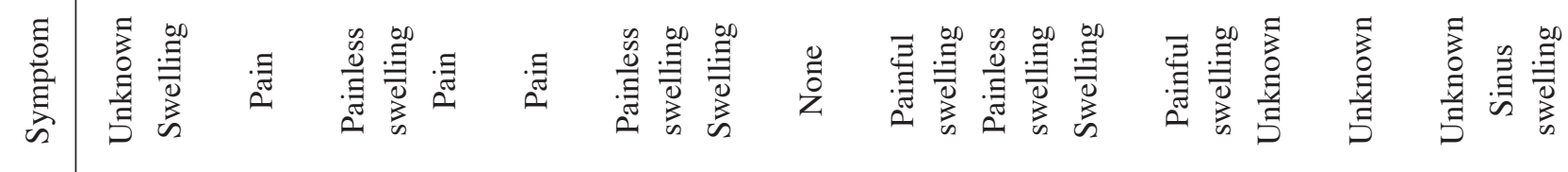

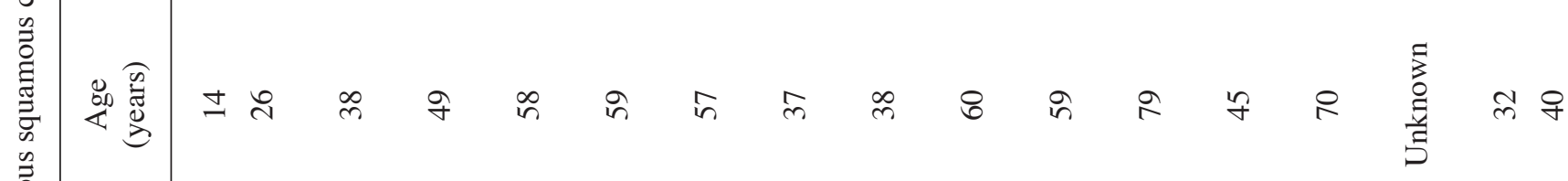

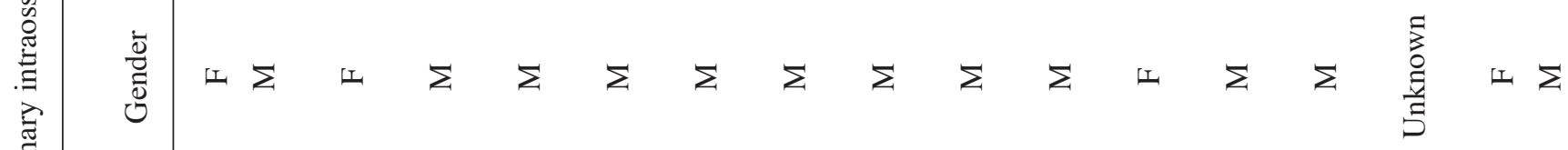

$$
\begin{aligned}
& \text { 竞 } \\
& \text { 矛 }
\end{aligned}
$$




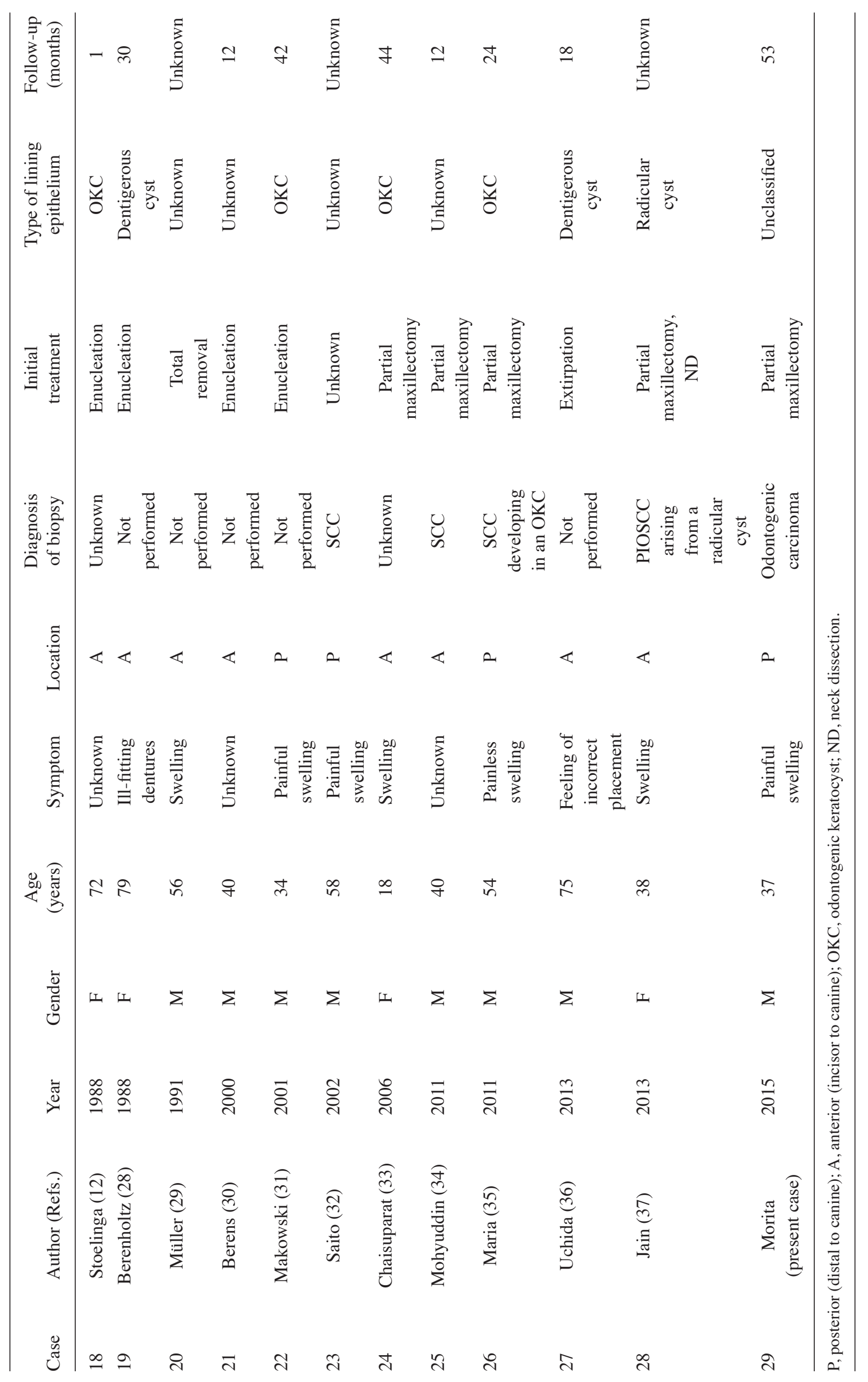




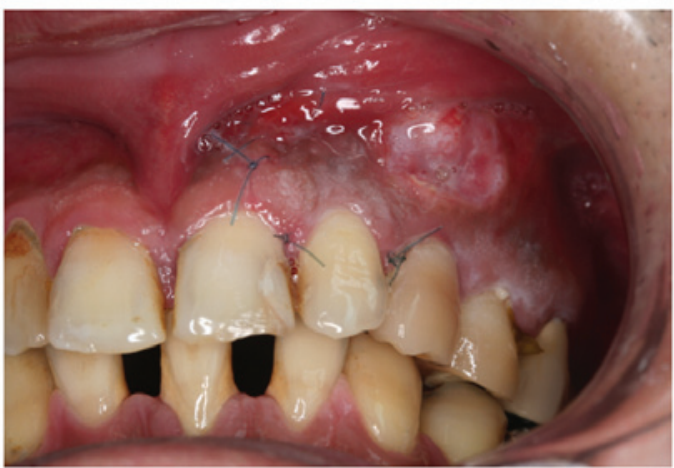

Figure 1. Intraoral photograph showing a swelling and an ulcer in the maxillary buccal gingiva of the left canine from a previous biopsy.

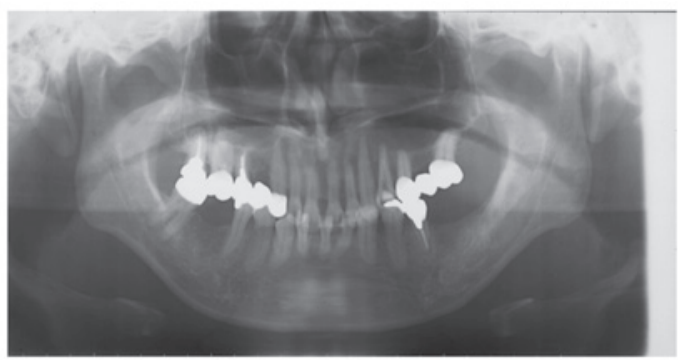

Figure 2. Panoramic radiograph showing no obvious cyst-like radiolucent lesion in the left maxilla.
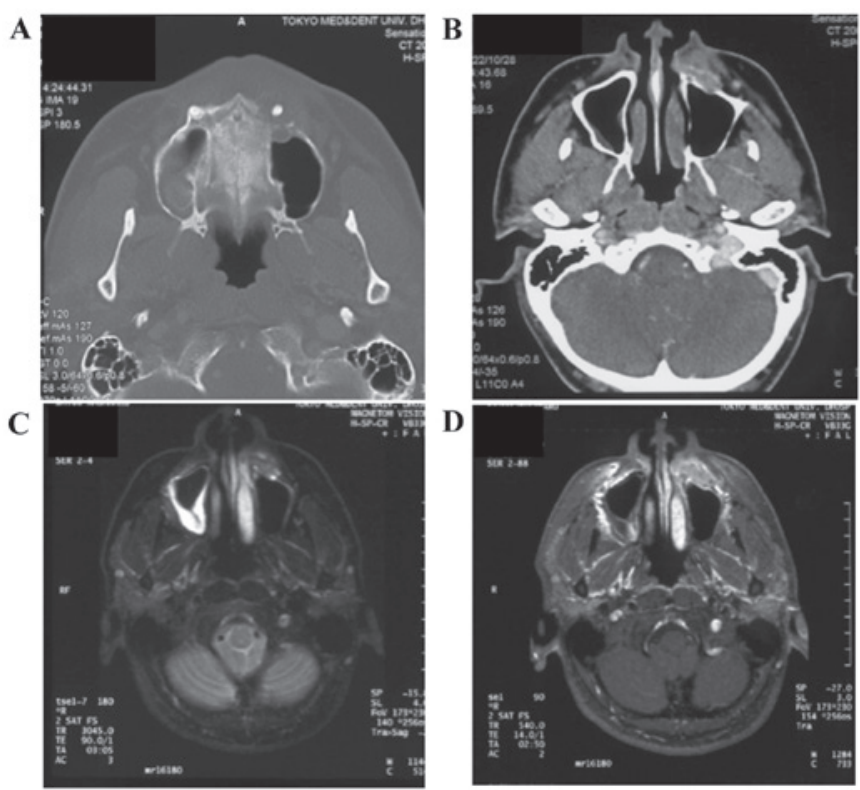

Figure 3. (A and B) Contrast-enhanced (CE) computed tomography (CT) and (C and D) CE-magnetic resonance imaging (MRI). (A) Axial CT image showing a soft tissue mass $\left(30 \times 16 \times 22 \mathrm{~mm}^{3}\right)$ with irregular borders. (B) The lesion exhibited heterogenous density, invading and damaging the left lateral nasal wall and left bottom edge of the left maxillary sinus. (C) Axial MRI showing a high-density on a T2-weighted image, indicating expansion of the tumor to the base of the left nasal ala. (D) The lesion exhibited gadolinium enhancement.

may be that the previous reports also included other types of odontogenic carcinoma, since the definition of PIOSCC has been modified several times.
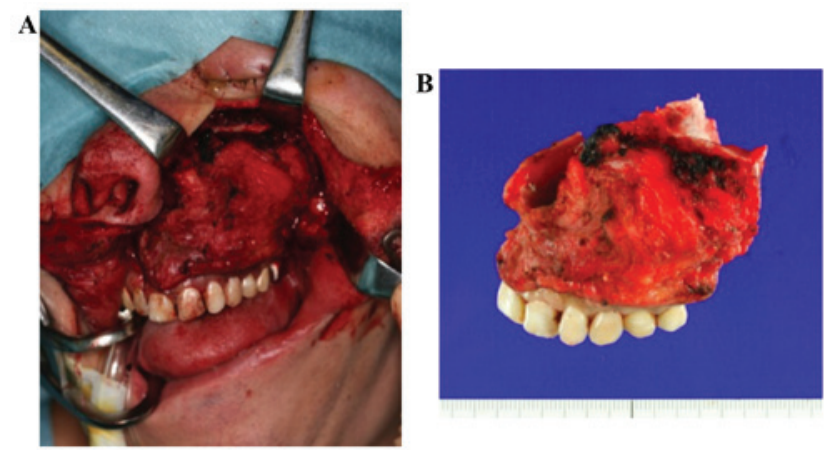

Figure 4. Weber-Ferguson incision. (A) Surgical specimen consisting of the maxilla from the right maxillary central incisor area to the left maxillary first molar area.
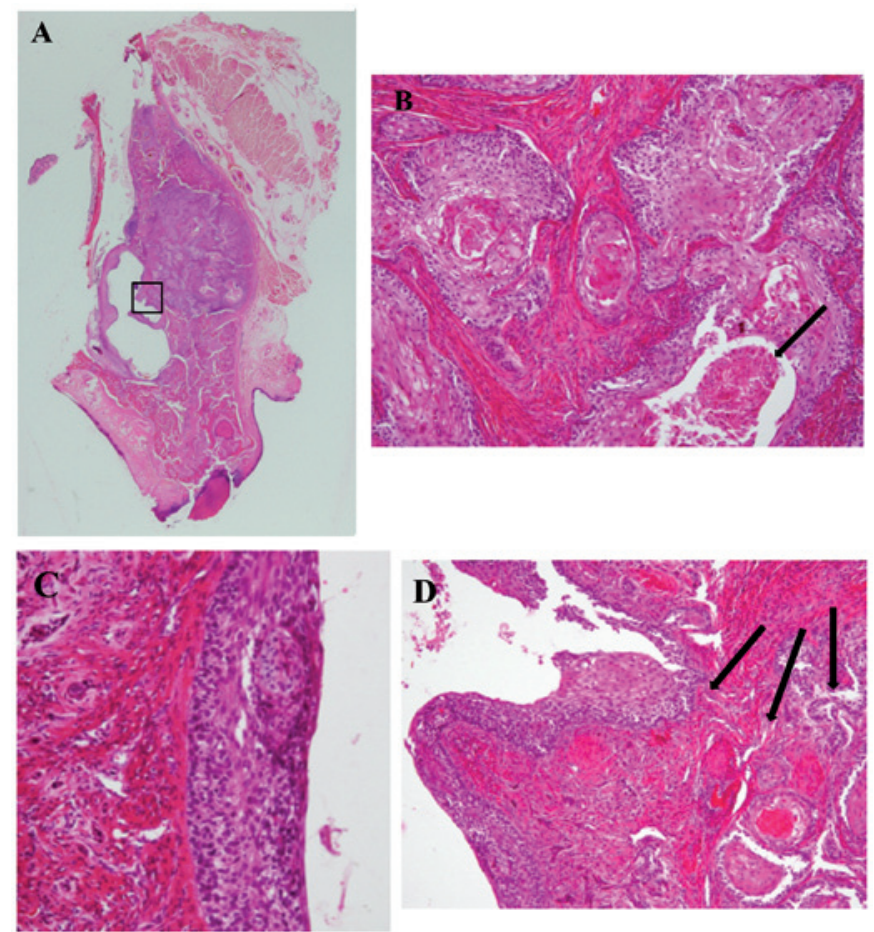

Figure 5. Histopathological findings. (A) The tumor mass including a cystic lesion was centrally located within the maxillary bone. A higher magnification of the square in $\mathrm{A}$ is shown in $\mathrm{D}$ [hematoxylin and eosin $(\mathrm{H} \& \mathrm{E})$ staining; magnification, x1]. (B) In the solid components, well-differentiated keratinizing squamous cell carcinoma nests are observed. Arrow, central necrosis in a cancer nest (H\&E staining; magnification, $x 100)$. (C) In the cystic lesion, the lining epithelium occasionally displayed a moderate to severe dysplastic appearance (H\&E staining; original magnification, x200). (D) Dysplastic lining epithelium transiting to invasive carcinoma, as indicated by the arrows (H\&E staining; original magnification, $\mathrm{x} 100$ ).

Various odontogenic cysts have been reported to be associated with PIOSCC. Certain types of odontogenic cysts, such as residual cysts, dentigerous cysts and keratocystic odontogenic tumors, tend to undergo malignant transformation $(13,39,40)$. As described in Table I, although odontogenic keratocysts, which include orthokeratinized and parakeratinized variants, exhibited the highest incidence among odontogenic cysts, several reports have previously revealed the exact types of odontogenic cysts associated with malignant tumors. The present case exhibited parakeratosis of the lining epithelium 
of the cyst, while palisaded basal cells were not identified in the lining epithelium and the epithelial layer was too thin for accurately diagnosing a keratocystic odontogenic tumor. Therefore, the exact type of odontogenic cyst was difficult to diagnose in the present case.

In conclusion, this report described a case of PIOSCC derived from a maxillary odontogenic cyst, along with a review of 29 cases of PIOSCC with maxillary involvement, focusing on the clinical and histopathological findings. Due to the limitation of the small number of cases, the treatment approach for odontogenic carcinomas, including PIOSCC, has yet to be standardized. Therefore, careful documentation and follow-up are recommended for each case of type 2 PIOSCC.

\section{References}

1. Loos D: Central epidermoid carcinoma of the jaws. Dtsch Monatsschr Zahnheilk 31: 308, 1913.

2. Willis RA (ed): Pathology of Tumors. 1st edition. Butterworth \& Co., London, pp310-316, 1948.

3. Pindborg JJ, Kramer IRH and Torloni H (eds): Histological Typing of Odontogenic Tumors, Jaw Cysts and Allied Lesions. 1st edition. World Health Organization, Geneva, pp35-36, 1972.

4. Elzay RP: Primary intraosseous carcinoma of the jaws. Review and update of odontogenic carcinomas. Oral Surg Oral Med Oral Pathol 54: 299-303, 1982

5. Slootweg PJ and Muller H: Malignant ameloblastoma or ameloblastic carcinoma. Oral Surg Oral Med Oral Pathol 57: 168-176, 1984.

6. Waldron CA and Mustoe TA: Primary intraosseous carcinoma of mandible with probable origin in an odontogenic cyst. Oral Surg Oral Med Oral Pathol 67: 716-724, 1989.

7. Eversole LR, Siar CH and van der Waal I: Primary intraosseous squamous cell carcinomas. In: World Health Organization Classification of Tumors. Pathology and Genetics Head and Neck Tumors. Barnes L, Evson JW, Reichart P and Sidransky D (eds.). IACR Press: Lyon, pp290-291, 2005.

8. Gardner AF: A survey of odontogenic cysts and their relationship to squamous cell carcinoma. Dent J 41: 161-167, 1975.

9. Otten JE, Joos U and Schilli W: Carcinogenesis in the apex of the cyst-forming odontogenic epithelium. Dtsch Zahnhartl Z 40: 544-547, 1985 (In German).

10. Kreidler J, Haas S and Kamp W: Carcinogenesis in jaw cyst. 2 case reports. Dtsch Zahnhartl Z 40: 548-550, 1985 (In German).

11. van der Waal I, Rauhamaa R, van der Kwast WA and Snow GB: Squamous cell carcinoma arising in the lining of odontogenic cysts. Report of 5 cases. Int J Oral Surg 14: 146-152, 1985.

12. Stoelinga PJ and Bronkhorst FB: The incidence, multiple presentation and recurrence of aggressive cysts of the jaws. J Craniomaxfac Surg 16: 184-195, 1988.

13. Bodner L, Manor E, Shear M and van der Waal I: Primary intraosseous squamous cell carcinoma arising in an odontogenic cyst: A clinicopathologic analysis of 116 reported cases. J Oral Pathol Med 40: 733-738, 2011.

14. Gardner AF: The odontogenic cyst as a potential carcinoma: A clinicopathological appraisal. J Am Dent Assoc 78: 746-755, 1969.

15. Axhausen G: Die Kiefergeschwülste. Berichte vom IX Internationalen Zahnärztekongress der FDI, Wien, 1936.

16. Mann JB, Ash JE and Bernier JL: Atlas of dental and oral pathology. 3rd edition. American Dental Association, Chicago, 1944.

17. Frankl Z and Wiesner J: Cancer starting from a cyst. Dent Item Interest 71: 564, 1949.

18. Martensson G: Cyst and carcinoma of the jaws. Oral Surg Oral Med Oral Pathol 8: 673-681, 1955.

19. Kodel G: Zur Malignen Umwandlung odontogener Kieferzysten. Dtsch Zahn Mund Kieferhk 36: 89, 1961.
20. Williams IE and Newman CW: Squamous cell carcinoma associated with a dentigerous cyst of the maxilla. Review and report of a case. Oral Surg Oral Med Oral Pathol 16: 1012-1016, 1963.

21. Lee KW and Loke SJ: Squamous cell carcinoma arising in a dentigerous cyst. Cancer 20: 2241-2244, 1967.

22. Bannerjee SC: Squamous cell carcinoma in a maxillary cyst. Oral Surg Oral Med Oral Pathol 23: 193-200, 1967.

23. Hampl PF and Harrigan WF: Squamous cell carcinoma possibly arising from an odontogenic cyst: Report of a case. J Oral Surg 31: 359-362, 1973.

24. Areen RG, McClatchey KD and Baker HL: Squamous cell carcinoma developing in an odontogenic keratocyst. Report of a case. Arch Otolaryngol 107: 568-569, 1981.

25. Nithiananda S: Squamous cell carcinoma arising in the lining of odontogenic cyst. Br J Oral Surg 21: 56-62, 1983.

26. Pearcey RG: Squamous cell carcinoma arising in dental cyst. Clin Radiol 36: 387-388, 1985.

27. Siar CH and Ng KH: Squamous cell carcinoma in an orthokeratinised odontogenic keratocyst. Int J Oral Maxillofac Surg 16: 95-98, 1987.

28. Berenholz L,Gottlieb RD, Cho SY and Lowry LD: Squamous cell carcinoma arising in a dentigerous cyst. Ear Nose Throat 67: 764-766, 768, 1988.

29. Müller S and Waldron CA: Primary intraosseous squamous carcinoma. Report of two cases. Int J Oral Maxillofac Surg 20: 362-365, 1991.

30. Berens A, Kramer FJ, Kuettner C, Eckardt A and Kreft A: Growth of a squamous epithelial carcinoma in an odontogenic cyst. Mund Kiefer Gesichtschir 4: 330-334, 2000 (in German).

31. Makowski G, McGuff S and Van Sickels JE: Squamous cell carcinoma in a maxillary odontogenic cyst. J Oral Maxillofac Surg 59: 76-80, 2001.

32. Saito T, Okada H, Akimoto Y and Yamamoto H: Primary intraosseous carcinoma arising from an odontogenic cyst: A case report and review of the Japanese cases. J Oral Sci 44: 49-53, 2002.

33. Chaisuparat R, Coletti D, Kolokythas A, Ord RA and Nikitakis NG: Primary intraosseous odontogenic carcinoma arising in an odontogenic cyst or de novo: A clinicopathologic study of six new cases. Oral Surg Oral Med Oral Pathol Oral Radiol Endodod 101: 194-200, 2006.

34. Mohyuddin N and Yao M: Primary intraosseous carcinoma of the anterior maxilla: An unusual case and review of the literature. Ear Nose Throat J 90: E35-E37, 2011.

35. Maria A, Sharma Y and Chhabria A: Squamous cell carcinoma in a maxillary odontogenic keratocyst: A rare entity. Natl J Maxillofac Surg 2: 214-218, 2011.

36. Uchida K, Ochiai T, Sinohara A, Miki M, Muto A, Yoshinari N, Hasegawa $\mathrm{H}$ and Taguchi A: Primary intraosseous odontogenic carcinoma arising from a dentigerous cyst. J Hard Tissue Biol 22: 375-382, 2013

37. Jain M, Mittal S and Gupta DK: Primary intraosseous squamous cell carcinoma arising in odontogenic cysts: An insight in pathogenesis. J Oral Maxillofac Surg 71: e7-e14, 2013.

38. Nomura T, Monobe H, Tamaruya N, Kishishita S, Saito K, Miyamoto R and Nakao K: Primary intraosseous squamous cell carcinoma of the jaw: Two new cases and review of the literature. Eur Arch Otorhinolaryngol 270: 375-379, 2013.

39. Chantravekin Y, Rungsiyanont S, Tang P, Tungpisityotin M and Swasdison S: Primary intraosseous squamous cell carcinoma derived from odontogenic cyst: Case report and review of 56 cases. Asian J Oral Maxillofac Surg 20: 215-220, 2008.

40. Eversole LR, Sabes WR and Rovin S: Aggressive growth and neoplastic potential of odontogenic cysts: With special reference to central epidermoid and mucoepidermoid carcinomas. Cancer 35: 270-282, 1975. 